\title{
SISTEM PENDUKUNG KEPUTUSAN MENENTUKAN OBAT DIABETES TERBAIK MENGGUNAKAN METODE TOPSIS
}

\author{
Melati Sitinjak' ${ }^{1}$, Suhada $^{2}$, Rafiqa Dewi ${ }^{3}$ \\ ${ }^{1}$ Mahasiswa Program Studi Sistem Informasi, STIKOM Tunas Bangsa Pematangsiantar \\ ${ }^{2,3}$ Dosen AMIK Tunas Bangsa Pematangsiantar \\ Email: ${ }^{1}$ melatisitinjak05@gmail.com, ${ }^{2}$ suhada.atb@gmail.com, ${ }^{3}$ rafiqa@ amiktunasbangsa.ac.id
}

\begin{abstract}
Abstrak
Diabetes melitus atau penyakit kencing manis, terjadi akibat berkurangnya produksi hormon insulin yang berfungsi mengubah gula menjadi tenaga, serta mengubah kadar gula dalam tubuh yang berlebih menjadi lemak. Kondisi ini mengakibatkan terjadinya hiperglikemia yang pengularan glukosa dalam urine. Penyebab Diabetes yang lebih kompleks yaitu karena faktor keturunan, faktor lingkungan meliputi usia, obesitas, resistensi insulin, aktifitas fisik, dan gaya hidup penderita yang tidak sehat juga berperan dalam terjadinya diabetes.Tujuan dari penelitian ini yaitu untuk menghasilkan aplikasi sistem pengambilan keputusan menentukan obat diabetes terbsaik menggunakan metode topsis. Metode Topsis digunakan untuk mengambil alternatif solusi terbaik dengan memperhatikan jarak terdekat dari solusi ideal positif dan jarak terjauh dari solusi negatif, dalam menentukan obat diabetes terbaik berdasarkan kriteria - kriteria yang telah ditentukan, sehingga dapat direkomendasikan sebagai sistem pendukung keputusan berikutnya. Hasil dari penerapan metode TOPSIS ini dapat menghasilkan output berupa perangkingan dari obat diabetes dan menentukan obat diabetes yang memiliki nilai preferensi tertinggi diantara alternatif lainnya. Kriteria yang digunakan untuk menentukan obat diabetes terbaik sebanyak 5 yaitu: Khasiat Obat, Indikasi Obat, Efek Samping, Harga Obat, Garansi Obat. Aplikasi ini dibangun dengan menggunakan bahasa pemograman web dan database Mysql.
\end{abstract}

Kata Kunci : Sistem pendukung Keputusan, Obat Diabetes, TOPSIS, Web, MySql

\begin{abstract}
Diabetes mellitus or diabetes, occurs due to reduced production of the hormone insulin which functions to convert sugar into energy, and convert excess sugar levels in the body into fat. This condition results in the occurrence of hyperglycemia which transmits glucose in the urine. The more complex causes of diabetes are due to heredity, environmental factors include age, obesity, insulin resistance, physical activity, and unhealthy lifestyle of patients also play a role in the occurrence of diabetes. The purpose of this study is to produce a decision making system to determine diabetes medications best using the topsis method. The Topsis method is used to take the best alternative solution by paying attention to the shortest distance from the positive ideal solution and the farthest distance from the negative solution, in determining the best diabetes drug based on predetermined criteria, so that it can be recommended as the next decision support system. The results of the application of the TOPSIS method can produce output in the form of ranking of diabetes drugs and determine diabetes drugs that have the highest preference value among other alternatives. The criteria used to determine the best diabetes drugs are 5, namely: Drug Efficacy, Drug Indications, Side Effects, Drug Prices, Drug Guarantees. This application was built using web programming language and Mysql database.
\end{abstract}

Keywords: Decision support system, Diabetes Medication, TOPSIS, Web, MySql

\section{PENDAHULUAN}

Di era globalisasi perkembangan yang pesat tidak hanya teknologi perangkat keras dan perangkat lunak, tetapi metode komputasi juga ikut berkembang. Salah satu cabang kecerdasan buatan yang berkembang saat ini adalah metode sistem pengambilan keputusan (Decision Support System). Sistem Pendukung Keputusan adalah sistem yang dapat membantu seseorang dalam mengambil keputusan yang akurat dan tepat sasaran. Sebagai contohnya adalah algoritma TOPSIS (Technique For Other Reference By Similiarity To Ideal Solution) merupakan Sistem yang digunakan untuk membantu dalam memilih alternatif terbaik berdasarkan kriteria - kriteria yang telah ditentukan.

Algoritma TOPSIS (Technique For Other Reference By Similiarity To Ideal Solution) sangat berkembang dibidang pendidikan baik bagi pembuat jurnal, kalangan Mahasiswa dan Dosen. Metode TOPSIS ini diharapkan dapat memberikan hasil yang lebih baik dalam membantu menentukan sistem pendukung keputusan. Salah satu permasalahan yang terjadi bagi Dokter yang menangani pasien penderita penyakit diabetes di RSUD DR. Djasamen Saragih Pematangsiantar dalam menentukan obat penyakit diabetes terbaik, diantaranya hanya berdasarkan perkiraan yang bersifat manual, sehingga terjadi banyak kesalahan dalam penentuan Obat Diabetes Terbaik.

Diabetes melitus, atau yang biasa dikenal sebagai penyakit kencing manis, terjadi akibat berkurangnya produksi hormon insulin yang berfungsi mengubah gula menjadi tenaga, serta mengubah kadar gula dalam tubuh yang berlebih menjadi sistem lemak. Kondisi ini mengakibatkan terjadi hiperglikemia yang biasa ditandai dengan meningkatnya kadar glukosa dalam darah melebihi nilai normal disertai pengeluaran glukosa dalam urine. Penyebab Diabetes yang lebih kompleks yaitu karena faktor keturunan, faktor lingkungan meliputi usia, obesitas, resistensi insulin, aktifitas fisik dan gaya hidup penderita yang tidak sehat juga berperan dalam terjadinya diabetes. Dampak penyakit Diabetes bagi pasien yang muncul apabila tidak segera ditangani dapat mengganggu fungsi tubuh yang lain, misalnya komplikasi yang mengakibatkan masalah pada mata (bisa sampai menyebabkan kebutaan), gangren (luka pada kaki yang susah disembuhkan), penyakit jantung, ginjal, hipertensi 
dan stroke. Tidak akuratnya informasi bagi Pemerintah menjadi salah satu penyebab penanganan atau pelayanan yang diberikan pemerintah kepada masyarakat melalui Rumah Sakit terhadap kasus Penyakit Diabetes menjadi kurang optimal.

Penulis mengambil keputusan untuk mengatasi masalah ketidak akuratan informasi tersebut dengan cara menggunakan Sistem Pendukung Keputusan. Sistem Pendukung keputusan atau decision support systems merupakan suatu perangkat sistem yang mampu memecahkan masalah secara efisien dan efektif, yang bertujuan untuk membantu pengambilan keputusan memilih berbagai alternatif keputusan yang merupakan hasil pengolahan informasi yang diperoleh dengan menggunakan model pengambilan keputusan.

Metode yang digunakan dalam penelitian ini adalah Algoritma TOPSIS (Technique for Order Performance of Similarity to Ideal Solution) merupakan salah satu sistem pendukung keputusan multikriteria. Algoritma TOPSIS mempunyai prinsip bahwa alternatif yang terpilih harus mempunyai jarak terdekat dari solusi ideal positif dan mempunyai jarak terjauh dari solusi ideal negatif dari sudut pandang geometris dengan menggunakan jarak Euclidean (jarak antara dua titik) untuk menentukan kedekatan relatif dari suatu alternatif.

Sistem Pendukung Keputusan ini diharapkan dapat membantu menentukan obat diabetes terbaik sehingga pasien penyakit diabetes dapat ditangani melalui pelayanan yang terbaik yang diberikan pihak rumah sakit dengan memberikan obat diabetes terbaik. Berdasarkan uraian diatas penulis mengambil judul skripsi "Sistem Pendukung Keputusan menentukan Obat Diabetes Terbaik menggunakan metode TOPSIS',

\section{TEORITIS}

\subsection{Sistem Pendukung Keputusan}

Sistem Pendukung Keputusan adalah sistem informasi interaktif yang menyediakan informasi, pemodelan dan manipulasi data yang digunakan untuk membantu pengambil keputusan pada situasi semi terstruktur dan tak seorangpun tahu secara pasti bagaimana keputusan seharusnya dibuat [1].Sistem pendukung keputusan (SPK) adalah bagian dari sistem informasi berbasis komputer termasuk sistem berbasis pengetahuan atau manajemen pengetahuan yang dipakai untuk mendukung pengambilan keputusan dalam suatu organisasi atau perusahaan. Dapat juga dikatakan sebagai sistem komputer yang mengolah data menjadi informasi untuk mengambil keputusan dari masalah semiterstruktur yang spesifik. [2].

\subsection{Algoritma TOPSIS}

Technique for Order Performance of Similarity to Ideal Solution (TOPSIS) merupakan salah satu sistem pendukung keputusan multikriteria[3]. TOPSIS mempunyai prinsip bahwa alternatif yang terpilih harus mempunyai jarak terdekat dari solusi ideal positif dan mempunyai jarak terjauh dari solusi ideal negatif dari sudut pandang geometris dengan menggunkana jarak Euclidean (jarak antara dua titik) untuk menentukan kedekatan relatif dari suatu alternatif.[4].

Metode TOPSIS memiliki keuntungan sebagai berikut[5]:

1. Metode Topsis merupakan salah satu metode yang simple dan konsep rasional yang mudah dipahami.

2. Metode Topsis mampu untuk mengukur kinerja relatif dalam membentuk form matematika sederhana.

Adapun langkah - langkah algoritma dari metode Topsis adalah:

1. Menentukan normalisasi matriks keputusan. Nilai ternormalisasi rij dihitung dengan rumus:

$$
r_{i j}=\frac{X_{i j}}{\sqrt{\sum_{i=1}^{m} X_{i j}^{2}}}
$$

Dimana :

rij = hasil dari normalisasi matriks keputusan $\mathrm{R}$

$\mathrm{i}=1,2 \ldots . . \mathrm{m}$

$\mathrm{j}=1,2 \ldots . . \mathrm{n}$

2. Membuat matriks keputusan yang ternormalisasi terbobot dengan bobot $\mathrm{W}=(\mathrm{w} 1, \mathrm{w} 2, \ldots \ldots \mathrm{Wn})$

$$
Y=\left[\begin{array}{ccc}
w_{1} r_{11} & w_{2} r_{12} & w_{j} r_{i j} \\
w_{1} r_{21} & \ldots & \ldots \\
w_{1} r_{i 1} & w_{2} r_{i 2} & w_{j} r_{i j}
\end{array}\right]
$$

3. Menentukan solusi ideal positif dan solusi ideal negatif

$\mathrm{A}^{+}=\mathrm{y} 1^{+}, \mathrm{y} 2^{+}, \ldots . ., \mathrm{yn}^{+}$

$\mathrm{A}^{-}=\mathrm{y} 1^{-}, \mathrm{y} 2^{-}, \ldots . ., \mathrm{yn}^{-}$

Dengan:

- max Yij, jika j adalah kriteria keuntungan

- min Y ij, jika j adalah kriteria biaya

$A j-$ adalah :

- min Yij, jika j adalah kriteria keuntungan 
- max Yij, jika j adalah kriteria biaya

4. Menentukan jarak antara nilai setiap alternatif dengan matriks solusi ideal dan matriks solusi ideal negatif. Jarak antara alternatif Ai dengan solusi ideal positif dirumuskan sebagai berikut:

$\mathrm{Di}^{+}=\sqrt{\sum_{\mathrm{j}=1}^{\mathrm{n}}\left(\mathrm{yi}^{+}-\mathrm{yi}\right)^{2}}$

5. Dimana $\mathrm{i}=1,2, \ldots, \mathrm{m}$ Jarak antara alternatif Ai dengan solusi ideal negatif dirumuskan sebagai berikut :

$$
\mathrm{Di}^{-}=\sqrt{\sum_{\mathrm{j}=1}^{\mathrm{n}}\left(\mathrm{yi}^{-}-\mathrm{yi}^{-}\right)^{2}}
$$

6. Menentukan nilai preferensi untuk setiap alternatif. Nilai preferensi untuk setiap alternatif (Vi) diberikan sebagai berikut :

$V i=\frac{D_{i}^{-}}{D_{i}^{-}+D_{i}^{+}}$

Dimana $\mathrm{i}=1,2, \ldots \mathrm{m}$

\subsection{Teknik Pengumpulan Data}

Pengumpulan data yang digunakan untuk memperoleh informasi adalah Metode Sampling adapun cara mendapatkan datanya yaitu : Kusioner, Observasi, Studi Pustaka.

\section{ANALISA DAN PEMBAHASAN}

\subsection{Data Kriteria dan Bobot}

Tabel 1. Kriteria dan Bobot

\begin{tabular}{lcl}
\multicolumn{1}{c}{ Kriteria } & Bobot & Keterangan \\
\hline Khasiat Obat & $30 \%$ & Benefit \\
Indikasi Obat & $25 \%$ & Benefit \\
Efek Samping & $15 \%$ & Cost \\
Harga Obat & $20 \%$ & Cost \\
Garansi Obat & $10 \%$ & Benefit \\
\hline
\end{tabular}

1. Normalisasi matriks keputusan

$$
\begin{aligned}
& |\mathrm{X} 1|=\sqrt{4^{2}+4^{2}+3^{2}+2^{2}+4^{2}+5^{2}+3^{2}+5^{2}+4^{2}}=11,6619 \\
& \mathrm{R} 11=\frac{4}{11,6619}=0,34300 \\
& \mathrm{R} 21=\frac{4}{11,6619}=0.34300 \\
& \mathrm{R} 31=\frac{3}{11,6619}=0,25725 \\
& \mathrm{R} 41=\frac{2}{11,6619}=0,17150 \\
& \mathrm{R} 51=\frac{4}{11,6619}=0,34300 \\
& \mathrm{R} 61=\frac{5}{11,6619}=0,42875 \\
& \mathrm{R} 71=\frac{3}{11,6619}=0,25725 \\
& \mathrm{R} 81=\frac{5}{11,6619}=0,42875 \\
& \mathrm{R} 91=\frac{4}{11,6619}=0,34300
\end{aligned}
$$

Sehingga diperoleh matriks normalisasi sebagai berikut:

$\mathrm{R}=\quad \begin{array}{lllll}0,3430 & 0,3050 & 0,2683 & 0,2394 & 0,3482 \\ 0,3430 & 0,4575 & 0,3578 & 0,3192 & 0,3482 \\ 0,2572 & 0,3050 & 0,3578 & 0,3192 & 0,3482\end{array}$




$\begin{array}{lllll}0,1715 & 0,1525 & 0,1789 & 0,2394 & 0,2611 \\ 0,3430 & 0,3050 & 0,3578 & 0,3192 & 0,2611 \\ 0,4287 & 0,3050 & 0,3578 & 0,3192 & 0,3482 \\ 0,2572 & 0,3050 & 0,3578 & 0,3990 & 0,2611 \\ 0,4287 & 0,3050 & 0,3578 & 0,3990 & 0,3482 \\ 0,3430 & 0,4575 & 0,3578 & 0,3990 & 0,4352\end{array}$

2. Membuat matriks keputusan ternormalisasi berbobot.

Pada tahap ini proses pembagian data obat diabetes menggunakan metode TOPSIS dan matriks keputusan ternormalisasi terbobot didapatkan dari perkalian matriks $\mathrm{R}$ dengan bobot preferensi.

Bobot ternormalisasi

$$
\begin{array}{ll}
\mathrm{Y}_{1.1}=0,30 * 0,3430=0,1029 & \mathrm{Y}_{1.2}=0,25 * 0,3050=0,0762 \\
\mathrm{Y}_{2.1}=0,30 * 0,3430=0,1029 & \mathrm{Y}_{2.2}=0,25 * 0,4575=0,1144 \\
\mathrm{Y}_{3.1}=0,30 * 0,2572=0,0772 & \mathrm{Y}_{3.2}=0,25 * 0,3050=0,0762 \\
\mathrm{Y}_{4.1}=0,30 * 0,1715=0,0514 & \mathrm{Y}_{4.2}=0,25 * 0,1525=0,0381 \\
\mathrm{Y}_{5.1}=0,30 * 0,3430=0,1029 & \mathrm{Y}_{5.2}=0,25 * 0,3050=0,0762 \\
\mathrm{Y}_{6.1}=0,30 * 0,4287=0,1286 & \mathrm{Y}_{6.2}=0,25 * 0,3050=0,0762 \\
\mathrm{Y}_{7.1}=0,30 * 0,2572=0,0772 & \mathrm{Y}_{7.2}=0,25 * 0,3050=0,0762
\end{array}
$$

3. Menentukan matriks ideal postif dan negative.

$$
\begin{aligned}
y 1+= & \max \{0,1029 ; 0,1029 ; 0,0772 ; 0,0514 ; 0,1029 ; 0,1286 ; 0,0772 ; 0,1286 ; 0,1029\} \\
& =0,1286 \\
y 1+= & \max \{0,0762 ; 0,1144 ; 0,0762 ; 0,0381 ; 0,0762 ; 0,0762 ; 0,0762 ; 0,0762 ; 0,1144\} \\
& =0,1144 \\
y 1-= & \min \{0,0402 ; 0,0537 ; 0,0537 ; 0,0268 ; 0,0537 ; 0,0537 ; 0,0537 ; 0,0537 ; 0,0537\} \\
& =0,0268 \\
y 1-= & \min \{0,0479 ; 0,0638 ; 0,0638 ; 0,0479 ; 0,0638 ; 0,0638 ; 0,0798 ; 0,0798 ; 0,0798\} \\
& =0,0479 \\
y 1+= & \max \{0,0348 ; 0,0348 ; 0,0348 ; 0,0261 ; 0,0261 ; 0,0348 ; 0,0261 ; 0,0348 ; 0,0435\} \\
& =0,0435 \\
\mathrm{~A}+= & \{0,12862 ; 0,1144 ; 0,0268 ; 0,0479 ; 0,0435\} \\
y 1+= & \min \{0,1029 ; 0,1029 ; 0,0772 ; 0,0514 ; 0,1029 ; 0,1286 ; 0,0772 ; 0,1286 ; 0,1029\} \\
& =0,0514 \\
y 1+= & \min \{0,0762 ; 0,1144 ; 0,0762 ; 0,0381 ; 0,0762 ; 0,0762 ; 0,0762 ; 0,0762 ; 0,1144\} \\
& =0,0381 \\
y 1-= & \max \{0,0402 ; 0,0537 ; 0,0537 ; 0,0268 ; 0,0537 ; 0,0537 ; 0,0537 ; 0,0537 ; 0,0537\} \\
& =0,0537 \\
y 1-= & \max \{0,0479 ; 0,0638 ; 0,0638 ; 0,0479 ; 0,0638 ; 0,0638 ; 0,0798 ; 0,0798 ; 0,0798\} \\
& =0,0798 \\
y 1+= & \min \{0,0348 ; 0,0348 ; 0,0348 ; 0,0261 ; 0,0261 ; 0,0348 ; 0,0261 ; 0,0348 ; 0,0435\} \\
& =0,0261 \\
\mathrm{~A}-= & \{0,0514 ; 0,0381 ; 0,0537 ; 0,0798 ; 0,0261\} \\
& =
\end{aligned}
$$

4. Menentukan jarak antara nilai negative dan matriks solusi ideal positif dan negative.

$$
\begin{aligned}
& \mathrm{D} 1+=\sqrt{\begin{array}{c}
(0,1029-0,1286)^{2}+(0,0762-0,1144)^{2}+(0,0402-0,0268)^{2} \\
+(0,0479-0,0479)^{2}+(0,0348-0,1144)^{2} \\
=0,0929
\end{array}} \\
& \mathrm{D} 2+=\sqrt{\begin{array}{c}
(0,1029-0,1286)^{2}+(0,1144-0,1144)^{2}+(0,0537-0,0268)^{2} \\
+(0,0638-0,0479)^{2}+(0,0348-0,1144)^{2} \\
=0,0893
\end{array}} \\
& \mathrm{D} 3+=\sqrt{\begin{array}{c}
(0,0772-0,1286)^{2}+(0,0762-0,1144)^{2}+(0,0537-0,0268)^{2} \\
+(0,0638-0,0479)^{2}+(0,0348-0,1144)^{2} \\
=0,1068
\end{array}}
\end{aligned}
$$

5. Menentukan prefensi untuk setiap alternatif.

Pada tahap ini hasil dari nilai V ( jarak kedekatan setiap alternatif terhadap solusi ideal diperoleh nilai yang memiliki nilai terbesar sehingga yang akan dipilih). 


$$
\begin{aligned}
& \mathrm{D} 1-=\sqrt{\begin{array}{c}
(0,1029-0,0514)^{2}+(0,0762-0,0381)^{2}+(0,0402-0,0537)^{2} \\
+(0,0479-0,0798)^{2}+(0,0348-0,0261)^{2} \\
=0,0733
\end{array}} \\
& \mathrm{D} 2-=\sqrt{\begin{array}{c}
(0,1029-0,0514)^{2}+(0,1144-0,0381)^{2}+(0,0537-0,0537)^{2} \\
+(0,0638-0,0479)^{2}+(0,0348-0,1144)^{2} \\
=0,0938
\end{array}}
\end{aligned}
$$

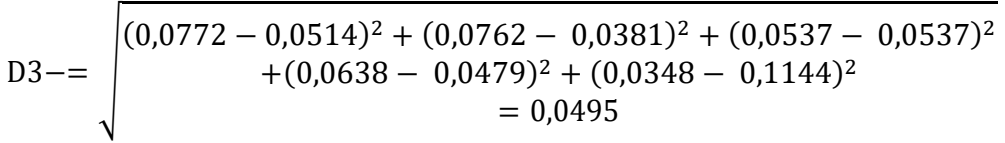

6. Menentukan nilai preferensi untuk setiap alternatif

$$
\begin{aligned}
& \mathrm{V} 1=\frac{0,0733}{0,0733+0,0929}=0,4412 \\
& \mathrm{~V} 2=\frac{0,0938}{0,0938+0,0893}=0,5123 \\
& \mathrm{~V} 3=\frac{0,0495}{0,0495+0,1068}=0,3165
\end{aligned}
$$

Tabel 2. Hasil akhir

\begin{tabular}{cccc}
\hline No & Alternatif & Nilai & Ranking \\
\hline 1 & Gliklazid & 0,4412 & 5 \\
2 & Glimepirid & 0,5123 & 2 \\
3 & Repaglinid & 0,3165 & 7 \\
4 & Nateglini & 0,2297 & 9 \\
5 & Metformin & 0,3875 & 6 \\
6 & Akarbose & 0,4846 & 3 \\
7 & Miglitol & 0,2826 & 8 \\
8 & Resiglitazon & 0,4699 & 4 \\
9 & Pioglitazion & 0,5208 & 1 \\
\hline
\end{tabular}

\subsection{Implementasi Program} 1.

Tampilan ini muncul pada saat pertama sekali program dijalankan. Tampilan log in dapat dilihat pada gambar

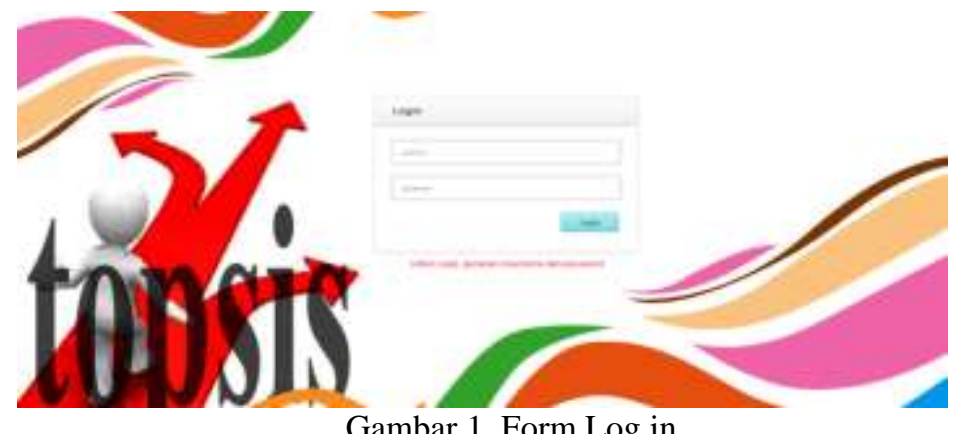

Gambar 1. Form Log in

Form ini menampilkan menu-menu yang ada pada form utama admin. Tampilan form utama dapat dilihat pada gambar 2 .

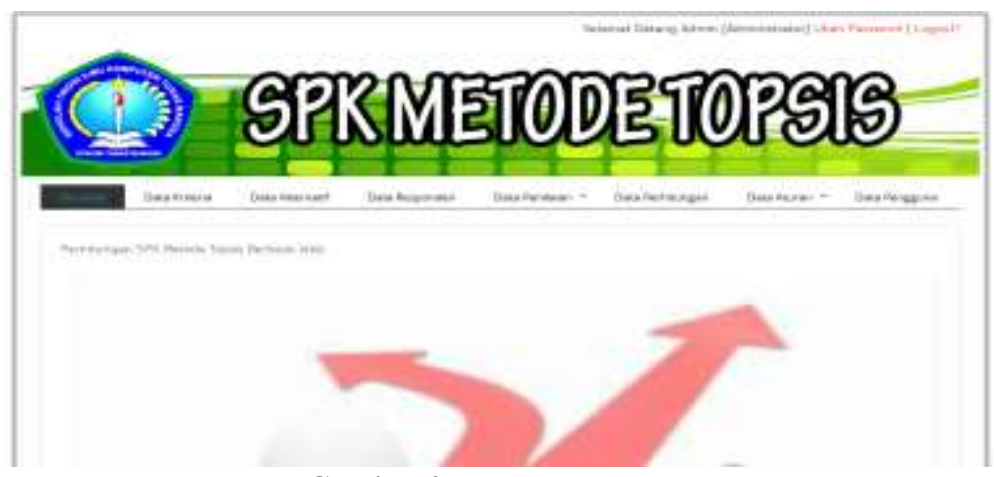

Gambar 2. Form Menu Utama 
Form ini menjelaskan bahwa kriteria yang digunakan untuk melakukan penilaian adalah Khasiat Obat, Indikasi Obat, Harga Obat,Garansi Obat.

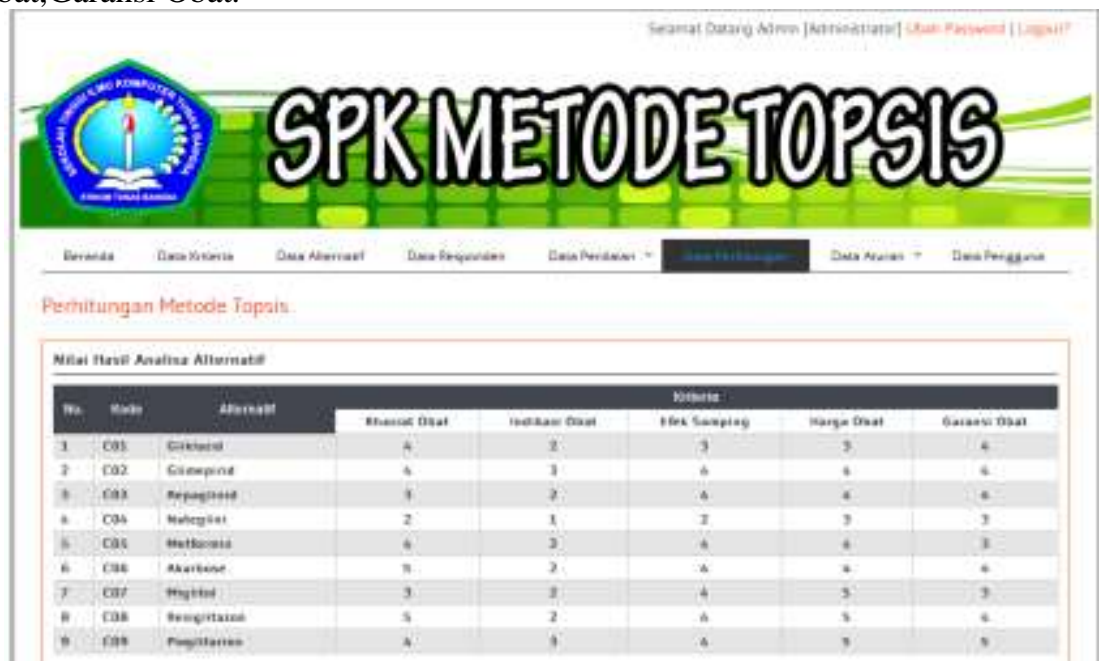

Gambar 3. Tampilan Form Hasil Analisa Perhitungan keperhitungan

Pada gambar diatas menjelaskan bahwa hasil analisa dimana nilai tersebut masih nilai data awal yang masuk Positit Negatif

\begin{tabular}{|c|c|c|c|c|c|c|c|}
\hline \multirow{2}{*}{ Ha. } & \multirow{2}{*}{ kode } & \multirow{2}{*}{ Alarnatt } & \multicolumn{5}{|c|}{ Kaillowa } \\
\hline & & & Cossint Obat & Intikasi obat & Eter 5ampiay & Harge osat & Garcosi 0bat \\
\hline 1 & $\cos$ & n* & 0,12862 & Q.11437 & 0.02683 & 0,06789 & $0,11 i 37$ \\
\hline 2 & $\cos$ & A. & 0,03145 & $0,038 \pm 2$ & 0,02683 & 0,0 main & 0,02611 \\
\hline & na & & Altanaitt & & A* & & A. \\
\hline & 1 & & NI & & 0,0529 & & 0,0733 \\
\hline & 2 & & $A 2$ & & 0,0893 & & 0,0971 \\
\hline & 3 & & No & & 0,1068 & & 0,0563 \\
\hline & 4 & & As & & 0,1399 & & 0,0319 \\
\hline & 5 & & AS & & 0,1043 & & 0,0712 \\
\hline & 6 & & A5 & & 0,0936 & & 0,0920 \\
\hline & 7 & & ND & & 0,1167 & & 0,0532 \\
\hline & a & & $A B$ & & 0,0576 & & 0.0906 \\
\hline & 9 & & AS & & 0,0861 & & $0,097 \mathrm{~h}$ \\
\hline
\end{tabular}

Gambar 4. Tampilan hasil solusi ideal positif dan solusi ideal negatif

Hasil dari Menentukan nilai preferensi dari setiap alternatif.

Setelah pemberian nilai maka sistem akan memproses hasil sistem seperti apa yang dilihat pada gambar 5 . adalah sebagai berikut

\begin{tabular}{c|l|c|c}
\hline NO & \multicolumn{1}{|c|}{ Alternatif } & Nilai & Ranking \\
\hline 1 & Gliklazid & 0,441173 & 5 \\
\hline 2 & Glimepirid & 0,522150 & 2 \\
\hline 3 & Repaglinid & 0,345061 & 7 \\
\hline 4 & Nateglini & 0,185838 & 9 \\
\hline 5 & Metformin & 0,405818 & 6 \\
\hline 6 & Akarbose & 0,495674 & 3 \\
\hline 7 & Miglitol & 0,313229 & 8 \\
\hline 8 & Resiglitazon & 0,481401 & 4 \\
\hline 9 & Pioglitazion & 0,530620 & 1 \\
\hline
\end{tabular}

Gambar 5. Tampilan Hasil Perhitungan

Pada gambar 5 diatas didapat hasil perhitungan dengan menggunakan Topsis. Dari hasil perhitungan tersebut didapat kesamaan nilai antara sistem dan perhitungan manual sehingga dapat disimpulkan bahwa perhitungan tidak ada kesalah antara sistem dan hitungan manual. 


\begin{tabular}{|c|c|c|c|c|}
\hline Mas & Kode & Alternafit & Maiai & Ranking \\
\hline 1 & $\operatorname{Cos}$ & Gliklazid & 0,661173 & 5 \\
\hline 2 & $\mathrm{CO} 2$ & Glimepirid & 0,5227150 & 2 \\
\hline 3 & $\cos$ & Repaglinid & 0,345061 & 7 \\
\hline 4 & $\cos$ & Nateglini & 0,185838 & 9 \\
\hline 5 & $\cos$ & Metformia & 0,405818 & 6 \\
\hline 6 & $\mathrm{COS}$ & Akarbose & 0,483613 & 1 \\
\hline 7 & $\mathrm{CO}$ & Miglitol & 0,313229 & 8 \\
\hline 8 & $\operatorname{COB}$ & Resiglitanon & 0,481401 & 4 \\
\hline 9 & $\cos$ & Pioglitarion & 0,530620 & 1 \\
\hline
\end{tabular}

Gambar 6. Perhitungan Algoritma Menggunakan Manual dan Aplikasi

Pengujian perhitungan manual yang diimplementasikan kedalam bentuk komputerisasi bertujuan untuk melihat kesesuaian hasil yang dieproleh antara perhitungan manual maupun secara komputerisasi. Jika hasil yang diperoleh menggunakan komputerisasi sesuai dengan perhitungan manual, maka kedepannya sistem yang dibangun mampu beroperasi di RSUD. Dr. Djasamen Saragih terkait guna membantu proses penentuan obat diabetes terbaik .

\section{KESIMPULAN}

Berdasarkan hasil penelitian, Untuk menentukan obat diabetes terbaik menggunakan Metode TOPSIS (Technique For Others Reference by Similarity to Ideal Solution) Penulis mengambil kesimpulan sebagai berikut :

1. Metode TOPSIS (Technique For Others Reference by Similarity to Ideal Solution) dapat menentukan obat diabetes terbaik, Penelitian ini menghasilkan bahwa Alternatif A6 (Akaborse) memiliki nilai tertinggi dalam menentukan obat diabetes terbaik.

2. Implementasi metode TOPSIS (Technique For Others Reference by Similarity to Ideal Solution) dengan perhitungan manual dan Sistem yang hasil akhirnya adalah perangkingan.

3. Dengan menerapkan metode TOPSIS (Technique For Others Reference by Similarity to Ideal Solution) kedalam web dengan menggunakan PHP My admin, XAMPP yang dapat membantu proses perhitungan

\section{REFERENCES}

[1] S. R. Ningsih, I. S. Damanik, I. Gunawan, And W. Saputra, Electre Dalam Menentukan Penerima Program Indonesia Pintar (Pip) Melalui Kartu Indonesia Pintar (Kip) (Studi Kasus: Sd Swasta Al - Washliyah Moho Kabupaten Simalungun), Komik(Konferensi Nas. Teknol. Inf. Dan Komputer), Vol. I, No. 1, Pp. 264-275, 2017.

[2] A. Triayudi And F. S. Hidayat, Sistem Pendukung Keputusan Penentuan Penerima Pinjaman Modal Dana Bergulir Koperasi Simpan Pinjam Pada Diskoperindag Kabupaten Serang Menggunakan Metode Topsis, Vol. 3, No. 1, Pp. 49-54, 2016.

[3] N. Aditya, Pemilihan Lokasi Sumber Pemilihan Lokasi Sumber Mata Air Untuk Pembangunan Jaringan Air Bersih Pedesaan Dengan Menggunakan Metode Topsis, Semin. Nas. Tek. Sipil V, Pp. 321-329, 2015.

[4] A. P. Windarto, Implementasi Metode Topsis Dan Saw Dalam Memberikan Reward Pelanggan, Kumpul. J. Ilmu Komput., Vol. 4, No. 1, Pp. 88-101, 2017.

[5] T. H. Mukti Et Al., Sistem Pemilihan Dosen Pembimbing Skripsi Dengan Metode Topsis ( Studi Kasus : Pendidikan Teknik Informatika ), Vol. 4, No. 1, Pp. 53-63, 2018. 